\title{
Effects of on-farm supplemental feeding of probiotic Bacillus subtilis on milk production in lactating dairy cows under tropical conditions
}

\author{
W. Choonkham ${ }^{1}$, J.T. Schonewille ${ }^{2}$, J.K. Bernard ${ }^{3}$ and W. Suriyasathaporn ${ }^{1,4,5}$ \\ ${ }^{1}$ Chiang Mai University, Faculty of Veterinary Medicine, Department of Food Animal Clinic, 50100 Chiang Mai, Thailand \\ ${ }^{2}$ Utrecht University, Faculty of Veterinary Medicine, Department of Farm Animal Health, Yalelaan 7, $3584 \mathrm{CL}$, Utrecht, Netherlands \\ ${ }^{3}$ University of Georgia, Department of Animal and Dairy Science, College of Agricultural and Environmental Sciences \\ 2360 Rainwater, GA 31793-5766, Tifton, United States \\ ${ }^{4}$ Chiang Mai University, Research Center of Producing and \\ Development of Products and Innovations for Animal Health and Production, 50100 Chiang Mai, Thailand
}

KEY WORDS: Bacillus subtilis, milk yield, milk composition, probiotic, tropics

Received: 23 September 2019

Revised: $\quad 15$ April 2020

Accepted: 1 September 2020

${ }^{5}$ Corresponding author:

e-mail: Suriyasathaporn@hotmail.com

\begin{abstract}
The objective of the study was to determine the effect of Bacillus subtilis supplementation on the production of heat-stressed cows in a tropical environment during summer and rainy seasons. Twenty-eight lactating crossbred Holstein-Friesian cows ( $89 \pm 50$ days in milk) on four farms in Thailand were randomly assigned to treatment sequences in a replicated $4 \times 4$ Latin square design. Each 21 days of experimental period included 13 days of adaptation followed by data collection from day 14 through 21 . A basal ration was fed to all cows. Cows were individually fed 0 (CON), $0.5 \times 10^{11}$ (BS0.5), $1 \times 10^{11}$ (BS1) or $2 \times 10^{11} \mathrm{CFU}(\mathrm{BS} 2)$ of $B$. subtilis/day. Throughout the study, microclimatic conditions inside the barns were recorded. Milk weights were measured on days 14 and 21, and milk samples were collected on day 21. Whole blood samples were collected for haematological and biochemical analyses only during the first period of the study. Milk yield increased $(P<0.01)$ linearly as the level of $B$. subtilis increased. The temperature-humidity index (THI) was negatively related to milk yield $(r=-0.52, P<0.01)$, protein $(r=-0.51, P<0.01)$ and lactose $(r=-0.49, P<0.01)$. Cows fed $B$. subtilis at the level of $2 \times 10^{11} \mathrm{CFU} /$ day produced $1.7 \mathrm{~kg} /$ day more milk. So, it was indicated that milk yield increased linearly with the level of supplemented $B$. subtilis, and the supplementation did not exert any effect on haematological and biochemical parameters.
\end{abstract}

\section{Introduction}

Heat stress is an important economically-relevant problem in the dairy industry around the world and occurs in environments with both high ambient temperature and high relative humidity. The extent of heat stress is determined by a temperature-humidity index (THI) (Armstrong, 1994). In general, physiological changes in heat-stressed cows include impaired rumen function (Bernabucci, 2012), decreased rumination time (Moretti et al., 2017) and feed intake (Wheelock et al., 2010) resulting in decreased milk production, reproductive efficiency and immune functioning. The initial heat stress (environment THI $>72$ ) and moderate heat stress (environment THI $>80$ ) induce panting, increased respiratory rate, lower feed intake, lower production performance, reduced fertility and increased early embryonic death (Jian et al., 2015). 
In order to reduce the heat stress, better provision of shade and evaporative cooling (Polsky and von Keyserlingk, 2017) and roughage quality have to be applied, but such methods are complicated and difficult to realise. Feeding animals additives containing live microorganisms (i.e. probiotics) is generally considered beneficial for the health of hosts (FAO, 2016). The results of the studies conducted in warmtemperature conditions (Peng et al., 2012; Sun et al., 2013) demonstrated that supplementation of Bacillus subtilis improves both rumen fermentation and lactation performance of dairy cattle.

A tropical environment is characterized by both high ambient temperature and high relative humidity. In most tropical countries, including Thailand, the THI is usually $>72$ and often $>80$ during the summer and rainy seasons. Under these conditions, the adverse effects of heat stress on performance, health and reproduction are persistent during the whole year (Boonkum et al., 2011; Polsky and von Keyserlingk, 2017). Due to the marked influence of heat stress on rumen fermentation and lactation performance in the tropical environment, the aforementioned promising results of probiotics on milk production in heatstressed cows were considered. So, the objective of this study was to determine if supplementation of B. subtilis would stimulate milk yield in heat-stressed cows in a tropical environment during summer and rainy seasons.

\section{Material and methods}

\section{Animal welfare}

All procedures were carried out following the principles and ethical guidelines for the use of animals for scientific purposes, and approved by the Animal Care and Use Committee of the Faculty of Veterinary Medicine, Chiang Mai University, Chiang Mai, Thailand (no. S23/2558).

\section{Cows, housing and feeding management}

The study was conducted on four randomly selected smallholder dairy farms with herds ranging from 10 to 20 crossbred Holstein-Friesian cows/farm from May to August 2016. The participating farms were selected based on the same size, basal rations and feeding practice. All farms are located near the Mae Wang Dairy Cooperative, Chiang Mai, Thailand (latitude: 18.616485, longitude: 98.812913; diameter $20 \mathrm{~km}$ ). Clinically healthy cows, free from mastitis based on the California Mastitis Test were selected for the trial. The selected cows on each farm were housed together with other cows in free stall barns and were fed rice straw and maize husk ad libitum supplemented with a commercial concentrate at the rate of $1 \mathrm{~kg}$ of concentrate per $2 \mathrm{~kg}$ of milk yield. Since roughages in Thailand are of low quality, the practice on giving a cow $1 \mathrm{~kg}$ of concentrate per $2 \mathrm{~kg}$ of milk yield is the routine practice for small holder dairy farms recommended by Department of Livestock Development, Ministry of Agriculture and Cooperative, Thailand. If cow produced $14 \mathrm{~kg}$ of milk per day, farmers give them $3.5 \mathrm{~kg}$ of concentrates during morning milking, and $3.5 \mathrm{~kg}$ of concentrates during evening milking. The pelleted concentrate ('Win W 95 SS', Lee Feed Mill Public Company Limited, Saraburi, Thailand) consisted of fish meal, soybean meal, maize meal, oil, bran, molasses, oyster shell, salt, trace minerals and vitamins. The same feeding was applied at each farm especially during the study period. Throughout the study, all cows had free access to the forage and fresh water. Inside each barn, electronic data loggers (Tenmars Electronics Co., Ltd., Taipei, Taiwan) registered the temperature and relative humidity hourly throughout the study. According to Boonkum et al. (2011) THI was calculated as:

$\mathrm{THI}=(1.8 \times \mathrm{T}+32)-[(0.55-0.0055 \times \mathrm{RH})$

$$
\times(1.8 \times \mathrm{T}-26)]
$$

where: $\mathrm{T}$-temperature expressed as ${ }^{\circ} \mathrm{C}$ and $\mathrm{RH}-$ relative humidity (\%).

\section{Experimental design}

Twenty eight dairy cows, including $4,12,8$ and 4 from farm A, B, C and D, respectively, were used to evaluate the effects of $B$. subtilis supplementation on milk yield and composition. The $B$. subtilis probiotic, with $>90 \%$ viability base according to information provided by the manufacturer (Sahathanee Co., Ltd, Bangkok, Thailand), was a mix of powdered $B$. subtilis solid-state fermentation products including defatted rice bran powder which was formed into a solid compact tablet containing $0.5 \times 10^{11} \mathrm{CFU}$ of $B$. subtilis (Relianz Vet Drug Co., Ltd., Bangkok, Thailand). At the beginning of the study, cows were characterised by (mean \pm standard deviation): $2 \pm 1$ lactations, $500 \pm 78 \mathrm{~kg}$ body weight, $89 \pm 50$ days in milk (DIM), and $15.8 \pm 3.1 \mathrm{~kg} /$ day milk. Animals were distributed to squares accordingly to initial milk yield. Within each square, cows were randomly assigned to treatment sequences in a replicated $4 \times 4$ Latin square design. The Latin square design was applied to the set of 4 cows in each farm. Therefore, 1, 3, 2 and 1 squares were applied to farm A, B, C and D, respectively. Each experimental period lasted 21 days, with 13 days for adaptation, and data collection from day 14 till day 21 . The four dietary treatments included a basal ration without $B$. subtilis $(\mathrm{CON})$, or the basal 
ration supplemented with either $0.5 \times 10^{11}(\mathrm{BS} 0.5)$, $1 \times 10^{11}(\mathrm{BS} 1)$ or $2 \times 10^{11}(\mathrm{BS} 2) \mathrm{CFU}$ of B. subtilis/cow/day. The treatment doses were based on the amounts previously determined by Peng et al. (2012, Sun et al. (2013) and Song et al. (2014). The B. subtilis preparation was fed in the morning.

\section{Sampling and chemical analysis}

On each farm, cows were milked twice a day at approximately 4:00 and 14:00. Individual milk weights were recorded on day 14 and 21 of each period. Individual milk samples were collected from two consecutive milkings on day 21 of each period and combined in a 1:1 ratio to form a composite for analysis. Milk samples were collected into plastic bottles, immediately placed on ice and transported to the laboratory. Then within $24 \mathrm{~h}$, samples stored at $4{ }^{\circ} \mathrm{C}$ were analysed for concentrations of fat, protein, lactose percentages and somatic cell count (SCC) using an automated milk analyser (FOSS, Hillerøed, Denmark). Yields of fat, protein and lactose were calculated using the corresponding milk yield.

Due to the fact of using higher than in previous studies (Peng et al., 2012; Sun et al., 2013) dose of $B$. subtilis (BS2), haematological and biochemical parameters were monitored during the first experimental period of the study. Whole blood samples were collected immediately prior to the beginning of the trial (week 0) and at the end of each week within first experimental period from the coccygeal vein or coccygeal artery following the morning feeding, variables were recorded: packed cell volume, red blood cell (RBC), mean corpuscular volume (MCV), haemoglobin, mean corpuscular haemoglobin concentration (MCHC), platelets, white blood cell (WBC), and WBC differential counts. The WBC differential counts were also determined microscopically on blood smears stained with Wright-Giemsa stain R V L Supply (Pathumthani, Thailand) for accuracy. Serum biochemical parameters analyses, i.e. urea nitrogen, creatinine, aspartate aminotransferase (AST), total protein, albumin and glucose were determined using an automated clinical chemistry analyser (Sysmex BX-3010, Sysmex Corporation, Kobe, Japan) with reagents provided by the manufacturer.

Rations were sampled at the end of each period in each farm and were stored at $-20^{\circ} \mathrm{C}$ until analysis. Dry matter (DM), crude protein (CP), ether extract (EE), crude fibre (CF) and ash were determined according to methods prescribed by AOAC International (AOAC International, 2000). CP was determined using the Kjeltec system (Kjeltec 2200, FOSS, Hillerøed, Denmark). EE was obtained using the Soxtec system (Soxtec 2055, FOSS, Hillerøed, Denmark). CF was analysed using the Fibertec system (Fibertec 2010, FOSS, Hillerøed, Denmark). Nitrogen free extract (NFE) was calculated as: $\mathrm{NFE}=\mathrm{DM}-(\mathrm{CP}+\mathrm{EE}+\mathrm{CF}+$ ash $)$. Total digestible nutrients (TDN) were calculated according to Harris et al. (1982). The average chemical composition (\% dry matter basis) of rations from the four selected farms is presented in Table 1.

Table 1. Chemical compositions of the basal rations fed at four selected farms during study period (means \pm standard deviation)

\begin{tabular}{llllllll}
\hline \multirow{2}{*}{ Rations } & \multirow{2}{*}{ DM, \% } & \multicolumn{6}{l}{ Chemical compositions on dry matter (DM) basis, \% } \\
\cline { 3 - 8 } & & CP & EE & CF & ash & NFE & TDN $^{1}$ \\
\hline Rice straw & $95.40 \pm 0.24$ & $4.87 \pm 0.06$ & $0.98 \pm 0.29$ & $37.1 \pm 0.91$ & $13.1 \pm 0.01$ & $43.9 \pm 0.57$ & $44.3 \pm 0.84$ \\
Dry maize husks & $91.50 \pm 2.90$ & $2.52 \pm 0.12$ & $1.44 \pm 0.28$ & $33.2 \pm 0.01$ & $2.21 \pm 0.03$ & $60.5 \pm 0.43$ & $54.8 \pm 0.47$ \\
Fresh maize husks & $21.08 \pm 0.95$ & $4.51 \pm 0.52$ & $1.94 \pm 0.39$ & $38.1 \pm 2.03$ & $2.62 \pm 0.14$ & $52.8 \pm 0.99$ & $57.5 \pm 1.74$ \\
Commercial concentrate & $91.47 \pm 0.58$ & $22.1 \pm 0.99$ & $7.73 \pm 1.21$ & $11.9 \pm 0.61$ & $8.53 \pm 0.31$ & $49.5 \pm 1.26$ & $76.9 \pm 1.94$ \\
\hline
\end{tabular}

$\mathrm{CP}$ - crude protein; EE - ether extract (crude fat); CF - crude fibre; NFE - nitrogen free extract = DM - (CP + EE + CF + ash); TDN - total digestible nutrients; ${ }^{1}$ values were calculated using formula according to Harris et al. (1982)

between 10:00 and 12:00 into EDTA, sodium fluoride (for glucose assay), or non-anticoagulant vacutainer tubes. The blood samples were immediately stored at $4{ }^{\circ} \mathrm{C}$ and submitted to the Veterinary Diagnostic Laboratory, Faculty of Veterinary Medicine, Chiang Mai University where the analyses of haematological and biochemical parameters were performed. Haematological parameters were performed using an automated haematology analyser (Mindray BC-5300Vet, Shenzhen Mindray Bio-Medical Electronics Co., Ltd, Shenzhen, China). The following

\section{Statistical analysis}

Data were analysed using the linear mixed model (MIXED procedure) of SAS University Edition (SAS Institute Inc., Cary, NC, USA) as a replicated 4 $\times 4$ Latin square design. The model included the fixed effects of square, treatment and period. Farm and cow within square were included as random effects. The SCC data were log transformed for analysis. Kenward-Roger option and first-order autoregressive covariance structure were used in the models. Data for haematological and biochemical parameters were 
analysed as repeated measures using the MIXED procedure of SAS with a model containing week 0 as covariate, fixed effects of treatment, sampling time, and the interaction between treatment group and sampling time, farm and cow within treatment group as random effect. The best covariance structure was selected based on Akaike's information criterion and Schwarz's Bayesian criterion among firstorder autoregressive, compound symmetry and unstructured. The values were presented as least squares means and standard error of the mean, which were compared using the Tukey adjustment. Orthogonal polynomials were used to test linear, quadratic and cubic effects in response to dietary probiotic levels of $B$. subtilis. Correlation coefficients among different variables were determined using the CORR procedure of SAS. Significance was declared at $P \leq 0.05$ and trends at $0.05<P \leq 0.10$.

\section{Results}

Milk yield increased linearly $(P<0.01)$ as B. subtilis supplementation increased (Table 2). Cows from group BS2 produced $1.7 \mathrm{~kg} /$ day more milk than animals from CON group. No statistically significant differences were observed in yield or concentration of milk components. Negative correlations (Table 3) were observed between increased DIM and milk yield $(\mathrm{r}=-0.56, P<0.01)$, and lactose percentage $(\mathrm{r}=-0.66, P<0.01)$. The THI gradually increased from 80.5 in the summer (May) to 82.4 in rainy season (August) (Figure 1). The high THI ( $>80)$ indicates that cows in the study were under moderate heat stress throughout the study. The THI was negatively correlated with yields of milk $(\mathrm{r}=-0.52, P<0.01)$, protein $(\mathrm{r}=-0.51, P<0.01)$ and lactose $(\mathrm{r}=-0.49, P<0.01)$ (Table 3$)$.

Table 2. Effect of dietary supplementation of Bacillus subtilis (BS) on milk yields and compositions

\begin{tabular}{|c|c|c|c|c|c|c|c|c|}
\hline \multirow{2}{*}{ Indices } & \multicolumn{4}{|c|}{ Treatment $^{1}$} & \multirow{2}{*}{ SEM } & \multicolumn{3}{|c|}{$P$-value - contrasts } \\
\hline & CON & BS0.5 & BS1 & BS2 & & linear & quadratic & cubic \\
\hline Milk yield, kg/day & $14.1^{\mathrm{a}}$ & $14.1^{\mathrm{ab}}$ & $14.6^{\mathrm{ab}}$ & $15.8^{b}$ & 1.110 & $<0.01$ & 0.52 & 0.72 \\
\hline Fat, $\%$ & 4.20 & 3.78 & 3.76 & 3.42 & 0.422 & 0.15 & 0.74 & 0.78 \\
\hline Protein, \% & 2.86 & 2.91 & 2.81 & 2.83 & 0.071 & 0.52 & 0.85 & 0.37 \\
\hline Lactose, $\%$ & 4.82 & 4.93 & 4.86 & 4.87 & 0.094 & 0.82 & 0.34 & 0.16 \\
\hline Fat yield, kg/day & 0.54 & 0.52 & 0.50 & 0.44 & 0.090 & 0.36 & 0.86 & 0.95 \\
\hline Protein yield, kg/day & 0.42 & 0.45 & 0.44 & 0.45 & 0.033 & 0.44 & 0.82 & 0.57 \\
\hline Lactose yield, kg/day & 0.72 & 0.76 & 0.76 & 0.79 & 0.064 & 0.39 & 0.85 & 0.78 \\
\hline $\mathrm{SCC}, \log _{10}$ cells $/ \mathrm{ml}$ & 5.13 & 4.86 & 5.28 & 5.10 & 0.917 & 0.81 & 0.93 & 0.21 \\
\hline
\end{tabular}

${ }^{1} \mathrm{CON}$ - no supplemental BS, BS0.5 - $0.5 \times 10^{11} \mathrm{CFU}$ BS/cow per day, BS1 - $1 \times 10^{11} \mathrm{CFU} \mathrm{BS} /$ cow per day, BS2 - $2 \times 10^{11} \mathrm{CFU}$ BS/cow/day; SEM - pooled standard error of the mean; SCC - somatic cell count; ${ }^{a b}-$ means within the same row with different superscripts are significantly different at $P \leq 0.05$

Table 3. Correlation between milk yield, milk composition, somatic cell count (SCC), days in milk (DIM) and temperature-humidity index (THI) ${ }^{1}$

\begin{tabular}{|c|c|c|c|c|c|c|c|c|c|c|}
\hline Indices & & $\%$ Fat & $\%$ Protein & $\%$ Lactose & Fat yield & Protein yield & Lactose yield & SCC & DIM & $\mathrm{THI}$ \\
\hline \multirow[t]{2}{*}{ Milk yield } & $r$ & -0.20 & -0.33 & 0.52 & 0.54 & 0.91 & 0.96 & -0.20 & -0.56 & -0.52 \\
\hline & $P$ & 0.30 & 0.02 & $<0.01$ & $<0.01$ & $<0.01$ & $<0.01$ & 0.15 & $<0.01$ & $<0.01$ \\
\hline \multirow[t]{2}{*}{$\%$ Fat } & $r$ & & 0.48 & -0.14 & 0.67 & 0.001 & -0.20 & 0.099 & 0.26 & 0.03 \\
\hline & $P$ & & $<0.01$ & 0.47 & $<0.01$ & 1.00 & 0.30 & 0.61 & 0.16 & 0.88 \\
\hline \multirow[t]{2}{*}{$\%$ Protein } & $r$ & & & -0.12 & 0.12 & -0.002 & -0.28 & 0.18 & 0.36 & 0.13 \\
\hline & $P$ & & & 0.40 & 0.52 & 0.99 & 0.05 & 0.19 & $<0.01$ & 0.35 \\
\hline \multirow[t]{2}{*}{$\%$ Lactose } & $r$ & & & & 0.15 & 0.47 & 0.63 & -0.32 & -0.66 & -0.25 \\
\hline & $P$ & & & & 0.42 & $<0.01$ & $<0.01$ & 0.02 & $<0.01$ & 0.07 \\
\hline \multirow[t]{2}{*}{ Fat yield } & $r$ & & & & & 0.66 & 0.51 & -0.25 & -0.11 & -0.29 \\
\hline & $P$ & & & & & $<0.01$ & $<0.01$ & 0.18 & 0.57 & 0.12 \\
\hline \multirow[t]{2}{*}{ Protein yield } & $r$ & & & & & & 0.93 & -0.089 & -0.49 & -0.51 \\
\hline & $P$ & & & & & & $<0.01$ & 0.54 & $<0.01$ & $<0.01$ \\
\hline \multirow[t]{2}{*}{ Lactose yield } & $r$ & & & & & & & -0.13 & -0.61 & -0.49 \\
\hline & $P$ & & & & & & & 0.33 & $<0.01$ & $<0.01$ \\
\hline \multirow[t]{2}{*}{ SCC } & $r$ & & & & & & & & 0.17 & 0.072 \\
\hline & $\mathrm{P}$ & & & & & & & & 0.22 & 0.61 \\
\hline
\end{tabular}

\footnotetext{
${ }^{1}$ significant correlations are in bold
} 


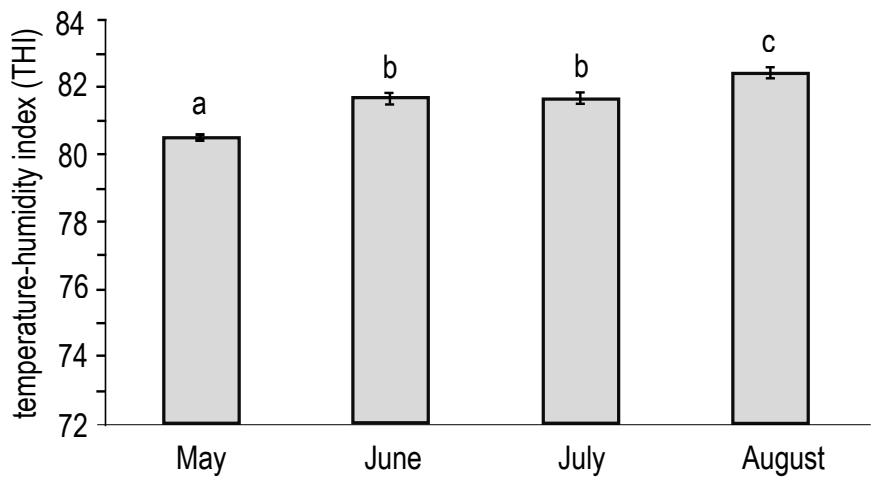

Figure 1. Mean and standard deviation of temperature-humidity indices (THI) recorded during the trial (from May to August). abc - bars with different superscripts are significantly different at $P<0.05$

Table 4. Effect of dietary supplementation of Bacillus subtilis (BS) on haematological and biochemical parameters among treatments during the first period of the study

\begin{tabular}{|c|c|c|c|c|c|c|c|c|c|c|c|}
\hline \multirow{2}{*}{ Indices } & \multicolumn{4}{|c|}{ Treatment $^{1}$} & \multirow{2}{*}{ SEM } & \multicolumn{3}{|c|}{$P$-value - effects } & \multicolumn{3}{|c|}{$P$-value - contrasts } \\
\hline & $\mathrm{CON}$ & BS0.5 & BS1 & BS2 & & treatment & time & treatment $\times$ time & linear & quadratic & cubic \\
\hline Packed cell volume, $\%$ & 27.0 & 26.7 & 24.8 & 23.5 & 1.47 & 0.27 & 0.87 & 0.37 & 0.06 & 0.92 & 0.66 \\
\hline $\mathrm{RBC}, \times 10^{6} / \mu \mathrm{l}$ & 5.70 & 5.94 & 5.25 & 4.94 & 0.381 & 0.10 & 0.65 & 0.05 & 0.02 & 0.75 & 0.26 \\
\hline MCV, fl & 48.5 & 46.5 & 49.1 & 48.0 & 2.04 & 0.79 & 0.54 & 0.34 & 0.94 & 0.98 & 0.32 \\
\hline Haemoglobin, g/dl & 9.37 & 9.25 & 8.36 & 7.91 & 0.548 & 0.10 & 0.58 & 0.04 & 0.02 & 0.83 & 0.50 \\
\hline $\mathrm{MCHC}, \mathrm{g} / \mathrm{dl}$ & 33.8 & 33.7 & 33.2 & 33.2 & 0.19 & 0.07 & $<0.01$ & 0.69 & 0.01 & 0.39 & 0.32 \\
\hline WBC, $\times 10^{3} / \mu \mathrm{l}$ & 10.1 & 11.3 & 14.2 & 11.7 & 2.06 & 0.65 & $<0.01$ & 0.07 & 0.52 & 0.30 & 0.58 \\
\hline Neutrophils, $\times 10^{3} / \mu \mathrm{l}$ & 3.36 & 4.19 & 3.71 & 3.33 & 0.593 & 0.69 & 0.03 & 0.24 & 0.72 & 0.43 & 0.50 \\
\hline Lymphocytes, $\times 10^{3} / \mu \mathrm{l}$ & 6.72 & 6.67 & 7.44 & 7.18 & 1.254 & 0.97 & 0.01 & 0.05 & 0.72 & 0.84 & 0.76 \\
\hline Monocytes, $\times 10^{3} / \mu \mathrm{l}$ & 0.47 & 0.64 & 0.51 & 0.51 & 0.070 & 0.35 & 0.50 & 0.03 & 0.88 & 0.40 & 0.16 \\
\hline Platelets, $\times 10^{3} / \mu \mathrm{l}$ & 333 & 398 & 324 & 425 & 55.9 & 0.50 & 0.23 & 0.57 & 0.32 & 0.72 & 0.30 \\
\hline Urea nitrogen, mg/dl & 7.99 & 7.64 & 8.22 & 7.74 & 1.071 & 0.94 & $<0.01$ & 0.51 & 0.90 & 0.86 & 0.58 \\
\hline Creatinine, $\mathrm{mg} / \mathrm{dl}$ & 1.57 & 1.52 & 1.52 & 1.53 & 0.069 & 0.94 & 0.05 & 0.97 & 0.69 & 0.68 & 0.84 \\
\hline AST, U/l & 87.1 & 91.8 & 71.1 & 73.2 & 10.85 & 0.39 & $<0.01$ & 0.12 & 0.16 & 0.76 & 0.29 \\
\hline Total protein, g/dl & 8.54 & 8.23 & 8.22 & 8.49 & 0.190 & 0.53 & 0.29 & 0.23 & 0.93 & 0.17 & 0.78 \\
\hline Albumin, g/dl & 3.56 & 3.53 & 3.40 & 3.38 & 0.094 & 0.37 & $<0.01$ & 0.01 & 0.11 & 0.64 & 0.58 \\
\hline Glucose, mg/dl & 58.1 & 60.6 & 55.4 & 54.4 & 2.92 & 0.23 & $<0.01$ & 0.90 & 0.09 & 0.82 & 0.20 \\
\hline
\end{tabular}

${ }^{1} \mathrm{CON}$ - no supplemental BS, BS0.5 - $0.5 \times 10^{11} \mathrm{CFU}$ BS/cow per day, BS1 - $1 \times 10^{11} \mathrm{CFU}$ BS/cow per day, BS2 - $2 \times 10^{11} \mathrm{CFU}$ BS/cow /day; SEM - pooled standard error of the mean; RBC - red blood cell; MCV - mean corpuscular volume; MCHC - mean corpuscular haemoglobin concentration; WBC - white blood cell; AST - aspartate aminotransferase

Haematological and biochemical parameters during the first period of the study are presented in Table 4. No differences $(P>0.05)$ were observed among treatments for haematological and biochemical parameters. Erythrocyte parameters including packed cell volume, RBC, haemoglobin and $\mathrm{MCHC}$ decreased linearly as supplementation of $B$. subtilis increased (all $P \leq 0.06$ ). Concerning leukocyte parameters, a tendency $(P=0.07)$ of treatment by time interaction for $\mathrm{WBC}$, a treatment by time interaction $(P=0.05)$ for lymphocytes were observed, and a treatment by time interaction $(P=0.01)$ was also observed for albumin, but comparisons using the Tukey adjustment indicated time effects within each treatment rather than treatment effects at individual time points. Glucose tended to decrease linearly as the level of $B$. subtilis increased $(P=0.09)$.

\section{Discussion}

Lactating dairy cows were used in the study as their milk yield had gradually declined to minimize physiological flotation of lactation performance (Moran, 2012). It is well recognized that heat stress negatively influences lactation performance (West, 2003). In contrast to other studies in which cows were housed in different environmental conditions, e.g., the comparison between thermal comfort zones and moderate heat stress (Salvati et al., 2015; Zhu et al., 2016), the current study was performed in an environment with THI ranging from 80.5 to 82.4 indicating that the cows experienced moderate heat stress (Polsky and von Keyserlingk, 2017) constantly during the whole experiment. The environmental conductions resulted in strong, 
negative correlations between THI and lactation performance which would be expected. Regardless of other management factors, many studies in either tropical environment (Boonkum et al., 2011) or temperate environment (Bouraoui et al., 2002; Hammami et al., 2013) also show the negative associations between increased THI and milk yield and composition.

While experiencing chronic moderate heat stress in this study, milk yield increased in response to supplementation of $B$. subtilis. Cows fed $2 \times 10^{11} \mathrm{CFU}$ of $B$. subtilis/day produced $1.7 \mathrm{~kg} /$ day more milk in comparison with $\mathrm{CON}$ group. These results are similar to those of Souza et al. (2017), who reported an increase of $1.7 \mathrm{~kg} /$ day in comparison with the control group when supplementing midlactation cows (DIM $=167 \pm 72$ at the beginning) with $3.9 \times 10^{9} \mathrm{CFU}$ of $B$. subtilis/day during a 16-week trial. Peng et al. (2012) and Sun et al. (2013) reported increases of 3.3 and $3.4 \mathrm{~kg}$ /day, respectively, in comparison with the control group when early-lactated cows' diets (DIM $=29 \pm 6$ and $\mathrm{DIM}=56 \pm 23$, respectively at the beginning) were supplemented with $1 \times 10^{11} \mathrm{CFU}$ of $B$. subtilis/day during a 9 -week trial. Our results indicated that milk yield increased linearly with increasing $B$. subtilis supplementation which is consistent with other studies (Peng et al., 2012; Sun et al., 2013). Also, no differences in yield or concentration of milk components were observed between late-lactating cows (DIM $=246 \pm 75$ at the beginning) fed diets supplemented with $B$. subtilis and control ones during a 39-day trial (Souza et al., 2017). In contrast, increased percentage and yield of milk protein and lactose were observed in early lactating cows fed supplemental B. subtilis (Peng et al., 2012; Sun et al., 2013). The differences observed in our study may be related to the tropical environment, stage of lactation and duration of supplementation. Peng et al. (2012) and Souza et al. (2017) reported significant differences in milk yields between animals fed diets supplemented with $B$. subtilis and control ones after 5 weeks of treatment.

Supplementation with $B$. subtilis might improve the health of cows under chronic moderate heat stress. Choonkham and Suriyasathaporn (2018) reported that periparturient cows fed diets supplemented with $B$. subtilis at $0.5 \times 10^{11} \mathrm{CFU} /$ day had lower risk of oxidative stress during the transition period under tropical conditions a factor related to the reduced milk production in heat-stressed cows (Guo et al., 2018). In poultry, supplementing $B$. subtilis under heat stress conditions improved the productive performance of broiler chickens (Gao et al., 2017; Wang et al., 2018) and laying hens (Fathi et al., 2018). Although, most of erythrocyte parameters and glucose decreased linearly as $B$. subtilis supplementation increased during the first period of the study, haematological and biochemical parameters in our study did not differ among treatments, and also were in line with the reference intervals established in the Animal Health Diagnostic Centre, College of Veterinary Medicine, Cornell University (Cornell University College of Veterinary Medicine, n.d.).

Supplementation of $B$. subtilis was reported to shift ruminal fermentation and promote greater propionate production (Peng et al., 2012; Sun et al., 2013). Propionate is converted to glucose which supports greater production of lactose in the mammary gland and therefore greater milk production (Rigout et al., 2003). Thus, lower blood levels of glucose were found in cows with higher milk yield (Bicalho et al., 2017).

\section{Conclusions}

The stimulatory effect of Bacillus subtilis supplementation on lactation performance was confirmed. Feeding $2 \times 10^{11} \mathrm{CFU}$ of B. subtilis/ day/cow can be effectively used to improve milk yield in moderate heat-stressed cows in a tropical environment. However, a cost-benefit analysis is needed to determine whether $B$. subtilis supplementation is a practical treatment for tropical dairy production systems. In addition, the underlying physiological mechanisms under heat stress conditions need further exploration.

\section{Acknowledgements}

This work was supported by the Faculty of Veterinary Medicine, Chiang Mai University and Thailand Research Fund (TRF) through the Research and Researcher for Industries (RRi) $\mathrm{PhD}$ Program. The authors also thank Mae-Wang dairy cooperative, and the staffs of Chiang Mai Artificial Insemination and Biotechnology Research Centre (Department of Livestock Development, Thailand) for their assistance during the research.

\section{References}

AOAC International, 2000. Official Methods of Analysis of AOAC International. $17^{\text {th }}$ Edition. Gaithersburg, MD (USA)

Armstrong D.V., 1994. Heat stress interaction with shade and cooling. J. Dairy Sci. 77, 2044-2050, https://doi.org/10.3168/jds. S0022-0302(94)77149-6 
Bernabucci U., 2012. Impact of hot environment on nutrient requirements. In: R.J. Collier, J.L. Collier (Editors). Environmental Physiology of Livestock. Wiley-Blackwell. Oxford (UK), pp. 101-128

Bicalho M.L.S., Marques E.C., Gilbert R.O., Bicalho R.C., 2017. The association of plasma glucose, BHBA, and NEFA with postpartum uterine diseases, fertility, and milk production of Holstein dairy cows. Theriogenology $88,270-282$, https://doi. org/10.1016/j.theriogenology.2016.09.036

Boonkum W., Misztal I., Duangjinda M., Pattarajinda V., Tumwasorn S., Sanpote J., 2011. Genetic effects of heat stress on milk yield of Thai Holstein crossbreds. J. Dairy Sci. 94, 487-492, https://doi.org/10.3168/jds.2010-3421

Bouraoui R., Lahmar M., Majdoub A., Djemali M., Belyea R., 2002. The relationship of temperature-humidity index with milk production of dairy cows in a Mediterranean climate. Anim. Res. 51, 479-491, https://doi.org/10.1051/animres:2002036

Choonkham W., Suriyasathaporn W., 2018. Antioxidant capacity of dairy cows after supplementation with dietary probiotic Bacillus subtilis during the transition period. In: Proceedings of American Dairy Science Assotiation Animal Meeting. June 24-27. Knoxville, TN (USA), abstract no.346

Cornell University College of Veterinary Medicine. (n.d.). Reference intervals, https://www.vet.cornell.edu/animal-health-diagnosticcenter/laboratories/clinical-pathology/reference-intervals

FAO (Food and Agriculture Organization of the United Nations), 2016. Probiotics in Animal Nutrition: Production, Impact and Regulation. Rome (Italy)

Fathi M., Al-Homidan I., Al-Dokhail A., Ebeid T., Abou-Emera O., Alsagan A., 2018. Effects of dietary probiotic (Bacillus subtilis) supplementation on productive performance, immune response and egg quality characteristics in laying hens under high ambient temperature. Ital. J. Anim. Sci. 17, 804-814, https://doi.org/10.1080/1828051X.2018.1425104

Gao Z., Wu H., Shi L., Zhang X., Sheng R., Yin F., Gooneratne R., 2017. Study of Bacillus subtilis on growth performance, nutrition metabolism and intestinal microflora of 1 to $42 \mathrm{~d}$ broiler chickens. Anim. Nutr. 3, 109-113, https://doi.org/10.1016/j. aninu.2017.02.002

Guo J., Gao S., Quan S., Zhang Y., Bu D., Wang J., 2018. Blood amino acids profile responding to heat stress in dairy cows. AsianAustralas. J. Anim Sci. 31, 47-53, https://doi.org/10.5713/ ajas. 16.0428

Hammami H., Bormann J., M'hamdi N., Montaldo H.H., Gengler N., 2013. Evaluation of heat stress effects on production traits and somatic cell score of Holsteins in a temperate environment. J. Dairy Sci. 96, 1844-1855, https://doi.org/10.3168/jds.20125947

Harris L.E., Leche T.F., Kearl L.C., Fonnesbeck P.V., Lloyd H., 1982. Central and Southeast Asia Tables of Feed Composition. International Feedstuffs Institute. Logan, UT (USA)

Jian W., Ke Y., Cheng L., 2015. Physiological responses and lactation to cutaneous evaporative heat loss in Bos indicus, Bos taurus, and their crossbreds. Asian-Australas. J. Anim. Sci. 28, 1558-1564, https://doi.org/10.5713/ajas.14.0526
Moran J. (Editor), 2012. Managing High Grade Dairy Cows in the Tropics. CSIRO Publishing. Clayton (Australia)

Moretti R., Biffani S., Tiezzi F., Maltecca C., Chessa S., Bozzi R., 2017. Rumination time as a potential predictor of common diseases in high-productive Holstein dairy cows. J. Dairy Res. 84, 385-390, https://doi.org/10.1017/S0022029917000619

Peng H., Wang J.Q., Kang H.Y., Dong S.H., Sun P., Bu D.P., Zhou L.Y., 2012. Effect of feeding Bacillus subtilis natto fermentation product on milk production and composition, blood metabolites and rumen fermentation in early lactation dairy cows. J. Anim. Physiol. Anim. Nutr. 96, 506-512, https://doi. org/10.1111/j.1439-0396.2011.01173.x

Polsky L., von Keyserlingk M.A.G., 2017. Invited review: Effects of heat stress on dairy cattle welfare. J. Dairy Sci. 100, 8645-8657, https://doi.org/10.3168/jds.2017-12651

Rigout S., Hurtaud C., Lemosquet S., Bach A., Rulquin H., 2003. Lactational effect of propionic acid and duodenal glucose in cows. J. Dairy Sci. 86, 243-253, https://doi.org/10.3168/jds. S0022-0302(03)73603-0

Salvati G.G., Morais Júnior N.N., Melo A.C., Vilela R.R., Cardoso F.F., Aronovich M., Pereira R.A., Pereira M.N., 2015. Response of lactating cows to live yeast supplementation during summer. J. Dairy Sci. 98, 4062-4073, https://doi.org/10.3168/jds.20149215

Song D.J., Kang H.Y., Wang J.Q., Peng H., Bu D.P., 2014. Effect of feeding Bacillus subtilis natto on hindgut fermentation and microbiota of holstein dairy cows. Asian-Australas. J. Anim. Sci. 27, 495-502, https://doi.org/10.5713/ajas.2013.13522

Souza V.L., Lopes N.M., Zacaroni O.F., Silveira V.A., Pereira R.A.N., Freitas J.A., Almeida R., Salvati G.G.S., Pereira M.N., 2017. Lactation performance and diet digestibility of dairy cows in response to the supplementation of Bacillus subtilis spores. Livest. Sci. 200, 35-39, https://doi.org/10.1016/j. livsci.2017.03.023

Sun P., Wang J.Q., Deng L.F., 2013. Effects of Bacillus subtilis natto on milk production, rumen fermentation and ruminal microbiome of dairy cows. Animal 7, 216-222, https://doi.org/10.1017/ S1751731112001188

Wang W.C., Yan F.F., Hu J.Y., Amen O.A., Cheng H.W., 2018. Supplementation of Bacillus subtilis-based probiotic reduces heat stress-related behaviors and inflammatory response in broiler chickens. J. Anim. Sci. 96, 1654-1666, https://doi. org/10.1093/jas/sky092

West J.W., 2003. Effects of heat-stress on production in dairy cattle. J. Dairy Sci. 86, 2131-2144, https://doi.org/10.3168/jds. S0022-0302(03)73803-X

Wheelock J.B., Rhoads R.P., Vanbaale M.J., Sanders S.R., Baumgard L.H., 2010. Effects of heat stress on energetic metabolism in lactating Holstein cows. J. Dairy Sci. 93, 644-655, https://doi. org/10.3168/jds.2009-2295

Zhu W., Zhang B.X., Yao K.Y., Yoon I., Chung Y.H., Wang J.K., Liu J.X., 2016. Effects of supplemental levels of Saccharomyces cerevisiae fermentation product on lactation performance in dairy cows under heat stress. AsianAustralas. J. Anim. Sci. 29, 801-806, https://doi.org/10.5713/ ajas. 15.0440 